\title{
A framework for reconciling user requirements and actual provision for Smart City implementation
}

\author{
Y. Mohd Adnan, H. Hamzah, M. N. Daud, M. M. Dali \& A. Alias \\ Faculty of Built Environment, University of Malaya, Malaysia
}

\begin{abstract}
The Smart City concept has been recognised as the way forward for cities that have strong ICT facilities and support. This concept provides the basis for a comprehensive city development strategy that could promote efficiency in city management and administration among city dwellers. Any city development concept must be formulated with the user and city characteristics in mind. The requirements of the city users are important in shaping the Smart City policies and programmes for the city. During the implementation of the Smart City initiatives, there is a need to ensure that the level of Smart City implementation matches user expectations. When the actual provision of Smart City features falls below user expectations, it can be said that there are gaps in the provision of Smart City initiatives for the city. The identification of these gaps would assist city managers in diverting more resources into the areas that need attention. This study proposes a framework for a gap analysis that indicates the achievement of required vs. actual Smart City initiative provision. Using Putrajaya, Malaysia as a case study, the intensity of initiative provision is calculated and then 'adjusted' against the intensity of user expectations to yield what is termed as Adjusted Level of Provision (ALP). Since the study has uncovered provision that needs improvement in turning Putrajaya as smart city, this framework could offer a useful tool for Smart City managers in measuring the city's performance.

Keywords: actual provision, smart city initiatives, user requirements.
\end{abstract}




\section{Introduction}

Many city development concepts have emerged over the last decade and the one that has become significant is the Smart City concept. In an increasingly connected and wired world, a city can be smarter through the enhancement of the city management systems to be competitively sustainable. It can be seen that when a city chooses to stay ahead in the aspect of sustainability, it has to turn into being "smart".

In the Eleventh Malaysia Plan (2016-2020) [1], the government has given an emphasis on the development of Smart City as it is seen as a way to revitalise development and provide advancement to new developing regions. For Putrajaya, the administrative city for Malaysia, Smart City can be adopted along with the current planned city development concept to complement the current initiatives for the further improvement of the city.

This study intends to present the idea of a Smart City framework into Putrajaya as an approach to upgrade the operation and administration of the city. It doesn't expect to change the current city development concept embraced by Putrajaya. In the current capacity, the adoption of Smart City initiatives for Putrajaya is seen as complementary to its present city administration arrangements. The sustainability of Putrajaya relies on upon its appeal to its users, namely the inhabitants, workers and visitors. Despite the fact that Putrajaya has been portrayed as a Smart Garden City [2], there have been reports of the lack of vibrancy in Putrajaya, referring to the absence of social, economic, social and knowledgeable activities within the city. This issue is not one of a kind to Putrajaya, but rather the lack of integration between the planned initiatives linking the various sustainability aspects.

As different urban communities in the world embrace the "Smart City" principles, Putrajaya has the potential of being turned into one as it was one of two selected urban zone under the Multimedia Super Corridor strategic plan introduced by the Malaysian government in 1996. The zone was to be developed by highinnovation organizations that Malaysia aspired towards the adaptation of California's Silicon Valley. The identified zone for this plan is within Cyberjaya, Kuala Lumpur City Center and Kuala Lumpur International Airport conurbation. Cyberjaya and Putrajaya - an area bounded by a fibre-optic system that provides the communication infrastructure. Since Putrajaya sits at the middle hub of this zone, stakeholders can depend on rapid internet access and other electronic-super highway provision, in accordance with the vision of electronic government (Othman [3]). The other 'Smart City' potential is Cyberjaya, an area which was planned for worldwide $R \& D$ with the ability to be the operational centre for multinational firms wishing to coordinate their overall activities utilizing interactive media innovation. Smart City is in this manner ought not to be an untimely vision for Putrajaya, yet rather a key move towards achieving the city's possibilities. 


\section{Defining Smart City for Putrajaya}

Having reviewed the various literature that has provided a range of various definitions for Smart City (Saad et al. [4]), this study has adopted the highly regarded earlier work by Giffenger et al. [5] which has identified six (6) dimensions of a Smart City as Smart Economy, Smart Governance, Smart People, Smart Mobility, Smart Environment and Smart Living. These dimensions have been adopted in Iskandar Malaysia, the pilot ongoing Smart City development in the southern region of Malaysia which is to act as a catalyst for growth. The Smart City dimensions include

- Smart Economy - focused on innovation, business enterprise, intellectual property, productivity and adaptability of the labour market;

- Smart People - is not just portrayed by the level of capability or training of the community but also through the nature of social collaborations and the openness towards the external world;

- Smart Governance - is shown through a society that has an open supporter of Agenda 21, access to government data, easiness of e-payment and eadministrations;

- Smart Mobility - alludes to the accessibility of data and latest information technologies and the feasible transport frameworks and utilization of open transportation;

- Smart Environment - appealing and available regular habitats and endeavours towards practicing environmental awareness to promote protection of the environment;

- Smart Living - contain different parts of personal satisfaction, for example, health, safety, wellbeing, security, housing and tourism (Musa $[6])$.

Since the 'Smart City' definition is still new in Malaysia, this study had made an attempt to uncover the criteria and initiatives for a smart city and to make a comparison of the various initiatives available from other comparable cities in the Asia Pacific region. This comparison has allowed a meaningful assessment of the current initiatives available in Putrajaya which can be adopted to expand the current Putrajaya's status as a green city.

\section{Putrajaya against selected Smart Cities}

Despite the fact that Putrajaya has not been planned as a Smart City, there are various city development initiatives implemented by the current city authority that could fit into the Smart City framework. These initiatives are comparable to the initiatives implemented in the identified Smart cities which were chosen for comparison. The observed initiatives from Seoul and Singapore were identified 
through site visits, observation and examination of related documents. It is useful to note that an earlier observation by ITU Technology Watch Report has revealed that various initiatives for a Smart City must address the city's functions and purposes [7].

The information gathered from the observation were utilised to create an assessment framework to uncover how diverse each city's initiative was in terms of the level of implementation. The results were initially arranged to show the level of implementation from lowest to highest levels from a scale of 1 to 4 . Nonetheless, this assessment is a subjective exercise using heuristic assessment to show the level of implementation. The heuristic investigation guided by the voluminous available information guided the task of ascertaining the levels for every smart level assessment for every city.

The findings of the observation made on the initiatives in Seoul and Singapore had revealed similar observation with the one mentioned by the ITU Technology Watch Report; in which both Seoul and Singapore have identified initiatives that address each city's vision and mission. It is found that both cities have achieved the highest level of implementation and the functions of the city and its institutional structure play a vital role in implementing the Smart City initiatives (Adnan et al. [8]).

When a similar exercise was conducted to indicate the level of implementation at Putrajaya, the outcomes from this activity uncovered Putrajaya's Smart City initiatives' achievement in various Smart City dimensions. Since Putrajaya is the new administrative centre of Malaysia with its new vision of turning into a green city, it has achieved the advanced level of achievement for initiatives under the Smart Environment and Smart Governance dimensions. In spite of the fact that Putrajaya was not intentionally plan as a Smart City, the conceptualisation of Smart City has portrayed the capability of Putrajaya in turning into a Smart City.

\section{Enhancing Putrajaya as a Smart City}

It is important to propose a Smart City framework for Putrajaya that fits in with the requirements of the Putrajaya's users' and the city's vision and mission. It is also argued that a city is unique because of the physical, demographic and socioeconomic characters that it has as opposed to those available at another city. Since this is the case, then it can be argued that an evaluation of a city's smartness in terms of the Smart City levels of initiative implementation ought to be made in relation to the city's own needs and aspirations. In the implementation of the Smart City initiatives, there is a need to ensure that the level of Smart City implementation matches user expectations. When the actual provision of Smart City initiatives falls below user expectations, it can be said that there are gaps in the provision. The identification of these gaps would assist the city authority to divert more resources into the areas that need attention. A gap analysis is suggested for the indication of the achievement of required vs. actual Smart City initiative provision. This gap will signify the extent to which the city would need to improve to become a truly 
smart city in its own right. A graphical representation of the proposed framework is shown as Figure 1 below.

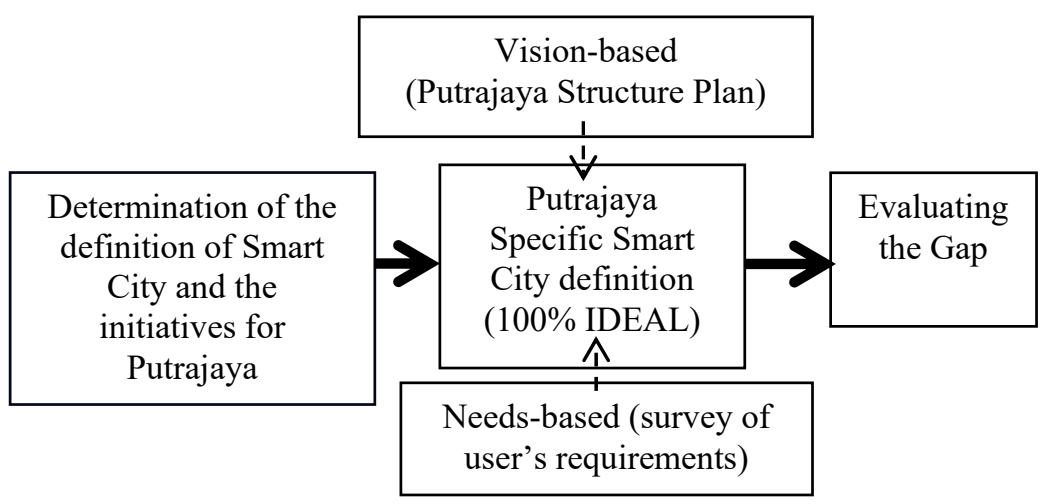

Figure 1: Smart City Gap framework.

\section{Assessment framework of the Smart City provision gap for Putrajaya}

The development of a model specifically for Putrajaya requires input that relates to Putrajaya itself. This means that the data to support the computation of both the smart 'ideal' for Putrajaya and smart 'actual' which represents the actual provision of the initiatives will have to be obtained from within Putrajaya. In order to gather the necessary input, ground observations and secondary data extracted from the official documents, including the Structure Plan [9] were gathered to identify the actual provisions. The 'ideal' case was identified through a survey among the users within Putrajaya. This exercise was made on the premise that users' rating of the importance also reflects to a significant extent of their expectation level.

The analysis of the gap survey was made through the use of the Adjusted Level of Provision (ALP) or also known as the 'Smartness Gap', which represent the extent to which current level of initiative provision falls short of the ideal. This gap analysis involved a comparison with Putrajaya's 'smartness ideal' against its 'smartness actual' to compute the difference. Data for 'smartness actual' came from a ground survey to ascertain the extent of the Smart City initiative provision that already existed in Putrajaya. Based on the observations and the implementation of the initiatives in Putrajaya, each Smart City initiative provision was heuristically assessed and rated on a scale of 1 to 4 , with each scale corresponding to a quartile. On 'smartness ideal' side, the data came from a questionnaire user survey to find out the level of importance that the Putrajaya users rate to the smart city initiatives provisions under each Smart City dimension, i.e. Smart Economy, Smart People, Smart Mobility, Smart Living, Smart Governance and Smart Environment. 
The intensity of initiative provision is calculated and then 'adjusted' against the intensity of user expectations to yield what we term as Adjusted Level of Provision (ALP). The ALP indicates the extent to which current level of initiative provision falls short of the ideal; the larger the number, the greater the shortfall. Calculating this way, it is also conceivable that we get a 'negative gap' as a possible outcome, which occurs when the score for ALP exceeds $100 \%$. This can happen when the existing level of initiative provision has exceeded what Putrajaya users' expectation, suggesting that Putrajaya should shift its focus away from this particular aspect of initiatives provision to reflect a more efficient use of resources.

\section{Findings}

The data for the user expectation is gathered from 680 respondents, comprising of 30 residents' associations, 349 residents and 301 employees/workers in Putrajaya. Having compared the actual provisions with the responses from the users' survey, the following findings are observed: 1) Putrajaya respondents consider important (as reflected by users' expectations) and place their expectations the highest on Smart Living and the lowest on Smart People dimensions by giving these the average scores. 2) In analysing these results, we find that Putrajaya still has satisfactorily achieved advance levels in all dimensions, but still with room for improvements in some Smart City initiatives. Smart Mobility, for example, scores the lowest to indicate that more initiatives need to be introduced in Putrajaya to enhance mobility. 3) A particularly interesting outcome of ALP analysis is the Smart Environment score surpasses the threshold for Putrajaya Smart City ideal on Environment. This indicated that Putrajaya has exceeded the initiative provision on smart environment and thus can somewhat shift its focus away from this area in order to concentrate more on other areas.

When comparison is made to the level of achievements for the initiatives under the six (6) Smart City dimensions, Putrajaya may not have achieved the highest level of provision as compared to the more developed cities. It has been observed that the Smart City dimension that has exceeded the 'Smart City Ideal' for Putrajaya is Smart Environment and this should be maintained in its quest of achieving the Sustainable Putrajaya vision. The current Green City development city concept has accommodated the 'Smart City Ideal' initiative provision. The dimensions that need improvement in order to attain similar levels with the other dimensions is Smart Mobility.

\section{Conclusion}

With the advancement of ICT and technology, the Smart City concept has been promoted to enhance the sustainability of the city's management. From Giffinger's model of six (6) Smart City dimensions, the various initiatives under each dimension can be identified for comparison purposes. Putrajaya, the administrative centre for Malaysia was not planned to be a Smart City. It was established 
following a specific function, i.e. to be an Administrative City that was planned based on the Intelligent city concept. However, cities need to adapt and evolve to stay relevant. Whilst Putrajaya did not have the high level of Smart City initiative implementation, it has the potential to be turned into one.

An important consideration has to be considered for the implementation of Smart City initiatives, i.e. various initiatives for a Smart City must address the city's functions and purposes [6]. The consideration recognises that every city is remarkable as far as its motivation and institutional make up, and rejects a onesize-fits-all strategy for applying the Smart City concept.

Through the use of the Adjusted Level of Provision (ALP) assessment framework, it provides a basis to examine the extent to which current level of initiative provision falls short of the ideal Smart City initiative provision for Putrajaya. It is found that at present, the Smart Mobility dimension indicated the biggest gap between user perspective and actual provision out of the six Smart City Dimensions. Thus, Smart Mobility has been identified as the dimension to receive further attention from Putrajaya city managers. Within the identification of the gap for the Smart City implementation, the ALP framework could offer a useful tool for Smart City managers in measuring the city's initiative's implementation.

It can also be recommended for Putrajaya to emulate the initiatives of the Smart City dimensions of Seoul and Singapore, although these initiatives are provided and created in relation to the purpose and role of each city. Such initiatives could be used as references towards the improvement of the smart city dimensions achievement for Putrajaya. Since Putrajaya had the initial status of an intelligent garden city, it certainly has the credentials to turn into a Smart City in realising its potential.

\section{References}

[1] Eleventh. Malaysia. Plan. 2016-2020, Economic Planning Unit, Prime Minister's Department, Malaysia.

[2] Malaysia Merdeka, www.malaysiamerdeka.gov.my/v2/

[3] Othman, A. From City in a Garden into a Pioneer Low Carbon Green City: Implementation of Green Initiatives in Putrajaya, Seminar ke arah Bandaraya: Implementasi Teknologi Hijau dan Pembangunan Mampan, 2012.

[4] Saad, M. S., Adnan, Y. M., Hamzah, H., Daud, M.N., Alias, A. and Dali, M.M, City Development Concepts for Sustainable Development, International Surveying Research Journal, Vol 4(2), pp. 1-22, 2014.

[5] Giffinger, R., Fertner, C., Kramar, H., Kalasek, R., Pichler-Milanovi, N., \& Meijers, E. Smart Cities: Ranking of European Medium-Sized Cities. Vienna, Austria: Centre of Regional Science (SRF), Vienna University of Technology, 2007.

[6] Musa, Z (2012, November). Iskandar Malaysia to be a model for other cities. The Star, www.iskandarmalaysia.com.my/news/121109/iskandar-malaysiato-be-a-model-for-other-cities 
[7] ITU-T Technology Watch Report 2013, Smart Cities - Seoul: a case study. 2013.

[8] Adnan, Y. M, Hamzah, H, Daud, Dali, M. M, Daud, M. N and Alias, A, Comparative Overview of Smart Cities Initiatives: Singapore and Seoul, Proc. of the $8^{\text {th }}$ International Real Estate Research Symposium, PWTC, Kuala Lumpur, 2016.

[9] Putrajaya Structure Plan 2025, Sustainable Putrajaya- From Garden to Green Perbadanan Putrajaya, 2012. 